\title{
Transition from metabolically healthy to unhealth status associated with risk of carotid artery plaque in Chinese adults
}

Tao Tan ${ }^{1+}$, Yiquan Zhou ${ }^{1 \dagger}$, Yanping Wan ${ }^{1,2}$, Zhuping Fan ${ }^{3}$, Renying $X u^{1,2^{*}}$ and Xiang Gao ${ }^{4}$

\begin{abstract}
Objective: We aimed to evaluate the association between the shift of metabolic status and future risk of carotid artery plaque (CAP) in community-based Chinese adults.

Methods: The current study included 9836 Chinese adults (4085 males and 5751 females, mean age 35.8 years) with metabolically healthy status at baseline (2013). Metabolically healthy status was defined as no self-reported history of metabolic diseases and cancer, and normal blood pressure, fasting blood glucose, glycated hemoglobin A1c level, and lipid profiles. Metabolically unhealthy status was defined if any of the following metabolic abnormalities were confirmed twice during follow up: high blood pressure, impaired glucose regulation, high triglycerides, high total cholesterol, high low-density lipoprotein cholesterols, or low high-density lipoprotein cholesterols. The transition was confirmed if participants' metabolic status shifted from baseline healthy to unhealthy status during follow up (2014-2018).
\end{abstract}

Results: We have identified 133 incident cases of CAP during follow up. Compared to those who remained metabolically healthy, the transition to high blood pressure, high total cholesterol, and high low-density lipoprotein cholesterols, were associated with high risk of developing carotid artery plaque (Hazards ratios (HRs) ranged from 1.69 to 2.34; $p<0.05$ for all). The transition to impaired glucose regulation, high total triglycerides, and low high-density lipoprotein cholesterols, were associated with high risk of carotid artery plaque only in participants with metabolically healthy overweight at baseline (HR ranged from 1.95 to 4.62; $p<0.05$ for all).

Conclusion: The transition from baseline metabolically healthy status to unhealth status was associated with high risk of incident CAP.

Keywords: Metabolically healthy status, Metabolically unhealthy status, Carotid artery plaque (CAP), Adults

\section{Introduction}

The presence of atherosclerosis obviously contributes to many adverse events, such as ischemic stroke, myocardial infarction, and impairment of cognitive function [1-3]. Further, one-third cardiovascular related deaths are

*Correspondence: xurenying7465@126.com

†Tao Tan and Yiquan Zhou contributed equally

${ }^{1}$ Department of Clinical Nutrition, Ren Ji Hospital South Campus, School

of Medicine, Shanghai Jiao Tong University, Shanghai 200127, China

Full list of author information is available at the end of the article resulted from atherosclerosis, thus making it the leading cause of mortality worldwide [4].

Metabolic abnormalities such as high blood pressure, impaired glucose regulation, and dyslipidemia are considered as three major contributing factors to atherosclerosis. Overweight and obesity are considered as the source of metabolic abnormalities, however, a specific obesity phenotype, named as "metabolically healthy obesity" [5], aroused the arguments. Previous studies generated mixed results: some studies reported a similar risk of 
developing atherosclerosis for metabolically healthy obesity to those with metabolically healthy normal weight [6-10], while others found that metabolically healthy obesity was also associated with a high risk of developing atherosclerosis, relative to their normal-weight counterpart [11-19]. However, some concerns need to be addressed. First, the heterogeneity among study design: most of them were cross-sectional studies [6, 8-10, 1219] and only 2 of them [7, 11] were cohort studies. Then, carotid intima-media thickness (IMT) $[6,8,9,11,14$, 16-18], coronary artery calcium score [7, 10, 12, 13, 15], and pulse wave velocity [19] were used to evaluate atherosclerosis. Finally, two studies $[11,14]$ were performed in men, one in women [18], one in patients with spinal cord injury [9], and others were in community population while sample size ranged from 38 [9] to 24,063 [10]. Existing evidences evaluating the association between baseline metabolically healthy obesity and CVD events also generated controversial results. For example, one national cohort study with long duration of follow up did not find the association between metabolically healthy obesity and ischemic stroke [20] while another national study reported metabolically healthy obesity increased the prevalence of stroke [21]. However, one meta-analysis only included prospective cohort studies reported that individuals with metabolically healthy obesity had an increased risk of stroke compared with metabolically healthy normal weight individuals $(\mathrm{RR}=1.17,95 \% \mathrm{CI}$ : 1.11-1.23) [22]. Further, the effects of the transition from metabolically healthy status to metabolic abnormalities on the development of atherosclerosis were neglected among previous studies. Data regarding the effects of the transition on the development of atherosclerosis is limited. To the best of our knowledge, only one cohort study to date evaluated the association of transition from metabolically healthy to unhealthy status with the development of atherosclerosis [23]. The transition, but not baseline metabolically healthy status, was associated with high risk of atherosclerosis [23]. However, it has been doubtful to classify individuals with one metabolic risk factors, such as high blood pressure or impaired glucose regulation, as metabolically healthy status [5]. Further, different metabolic abnormalities might exert different effects on the developing atherosclerosis, thus it is appropriate to evaluate these risk factors (such as high blood pressure, impaired glucose regulation) separately rather than combining them together [24].

Therefore, we performed the current study in community-based Chinese population with metabolically healthy status and followed them for five years. CAP (carotid artery plaque), which was assessed by ultrasound B model annually, was served as an indicator for systematic atherosclerosis [25]. We hypothesized that the transition from baseline metabolically healthy status to metabolic abnormalities was associated with future risk of CAP.

\section{Subjects and methods Study population}

All the participants were recruited from the Health Management Center in a teaching hospital from January 1, 2013 to December 31, 2018. The inclusion criteria were those: (1) who aged 18 years or more; (2) with normal blood pressure, fasting blood glucose (FBG), glycated hemoglobin A1c (HbA1c), lipid profile, and carotid artery B ultrasound assessment at baseline (2013). An initial recruitment resulted in an identification of 109,410 subjects. The total prevalence of metabolically healthy status was $31.2 \%$ and it was $44.4 \%, 17.7 \%$, and $7.1 \%$ respectively for participants with normal weight $\left(\mathrm{BMI}<24.0 \mathrm{~kg} / \mathrm{m}^{2}\right)$, overweight $\left(24.0 \mathrm{~kg} / \mathrm{m}^{2} \leq \mathrm{BMI}<28.0 \mathrm{~kg} / \mathrm{m}^{2}\right)$, and obesity $\left(\mathrm{BMI} \geq 28.0 \mathrm{~kg} / \mathrm{m}^{2}\right)$. Then, we performed a sequential recruitment. First, we excluded those with self-reported history of a series of metabolic diseases $(n=9622)$ and cancer $(n=29)$; Second, we excluded those with baseline metabolic abnormalities $(n=65,630)$; Third, we excluded those lost to follow up (2014-2018) $(\mathrm{n}=13,378)$ and with missing data $(\mathrm{n}=8083)$; Finally, we excluded those with low baseline BMI $\left(\leq 18.4 \mathrm{~kg} / \mathrm{m}^{2}\right)(\mathrm{n}=2674)$; (6) aged 65 years or more because there were only 79 participants. (7) with CAP at baseline $(\mathrm{n}=78)$; (8) with low eGFR $<60 \mathrm{ml} / \mathrm{min} / 1.73 \mathrm{~m}^{2}(\mathrm{n}=1)$. A total number of 9836 (4085 men and 5751 women, mean age of $35.8 \pm 9.0$ years) Chinese adults with metabolically healthy status (details were shown in Additional file 1: Fig. S1). Participants who were included in the study tended to be younger, had higher proportion of women and lower baseline BMI, level of HbA1c, FBG, and blood pressure, compared with those who were out of the study (Additional file 1: Table S1). The study protocol was approved by the Ethical Committee of Ren Ji Hospital, School of Medicine, Shanghai Jiao Tong University. As a de-identified secondary data analysis, patients' consent was waived.

\section{Assessment of body weight, blood pressure and biochemical parameters}

Body weight (to the nearest $0.5 \mathrm{~kg}$ ) and height (to the nearest $0.5 \mathrm{~cm}$ ) was measured in standing position without shoes and in light clothing, using an electronic scale (SK-CK, Shuang Jia Company, Shanghai, China). BMI was calculated by body weight $(\mathrm{kg})$ divided by height square $\left(\mathrm{m}^{2}\right)$. Blood pressure was measured twice using an automatic blood-pressure meter (HBP-9020, OMRON (China) Co., Ltd.) after participants were seated for at 
least $10 \mathrm{~min}$. The average of two measurements was recorded for further analysis.

Venous blood samples were drawn and transfused into vacuum tubes containing EDTA in the morning after participants were fasted for at least six hours. An automatic analyzer (Roche 701 Bioanalyzer, Roche, UK) was used to measure FBG with the hexokinase/glucose-6-phosphate dehydrogenase method. The level of HbA1c was measured by high performance liquid chromatography, using the fully automated VARIANT ${ }^{\mathrm{TM}}$ II Hemoglobin Testing System (Bio-Rad, U.S). Total cholesterol (TC), triglycerides (TG), low-density lipoprotein cholesterols (LDL-C), and high-density lipoprotein cholesterols (HDL-C) were measured by an automatic biochemical analyzer (Roche 701 Bioanalyzer, Roche, UK). The estimated glomerular filatration rate (eGFR) was calculated using the Chronic Kidney Disease Epidemiology Collaboration 2-level race equation [26]. The concentration of high sensitivity CRP (hs-CRP) was measured by immune-tubidimetric method. All the measurements were completed in the Clinical Laboratory of our hospital.

\section{Assessment of history of metabolic diseases}

The history of hypertension, diabetes/impaired glucose regulation, dyslipidemia, cardiovascular diseases (stroke, hemorrhage, coronary artery bypass grafting, stent surgery, and ischemic infarction), was collected via a selfreport questionnaire.

\section{Assessment of CAP (outcome)}

Ultrasound B-mode imaging was performed annually to detect CAP during five-year follow-up (Philips HDI 5000 ultrasound system equipped with a $7.5 \mathrm{MHz}$ probe). Intima-media thickness was measured at the point approximately $1.5 \mathrm{~cm}$ away from the distal part of the bifurcation of common carotid artery. CAP is defined as a focal region with a thickness $>1.5 \mathrm{~mm}$ as measured from the media adventitia interface to the lumen-intima interface or as the presence of focal wall thickening that is at least $50 \%$ greater than that of the surrounding vessel wall [27].

\section{Definition of metabolically healthy status and unhealth status}

Metabolically healthy status was defined as no selfreported history of metabolic diseases (hypertension, diabetes, dyslipidemia, and cardiovascular diseases) and cancer at baseline, and normal blood pressure, FBG, $\mathrm{HbA} 1 \mathrm{c}$, and lipid profiles. Metabolically unhealthy status was defined if any of the following metabolic abnormalities were confirmed twice during follow up: high blood pressure (systolic blood pressure $\geq 130 \mathrm{mmHg}$ or diastolic blood pressure $\geq 80 \mathrm{mmHg}$ ) [28], impaired glucose regulation ( $\mathrm{FBG} \geq 5.6 \mathrm{mmol} / \mathrm{L}$ or $\mathrm{HbA} 1 \mathrm{c} \geq 5.7 \%$ ) [29], high TC $(\geq 5.72 \mathrm{mmol} / \mathrm{L})$, high TG $(\geq 1.7 \mathrm{mmol} / \mathrm{L})$, high LDL-C $(\geq 3.4 \mathrm{mmol} / \mathrm{L})$, or low HDL-C $(<0.9 \mathrm{mmol} / \mathrm{L}$ in men and $<1.0 \mathrm{mmol} / \mathrm{L}$ in women). The transition was defined when participants' metabolic status shifted from baseline healthy to unhealthy status during follow up (2014-2018). In the current study, the transition was considered as the exposure. In the secondary analysis, we evaluated the associated between baseline body weight status (normal weight vs. overweight) and the risk of developing metabolic abnormalities. Participants were classified into normal weight $\left(18.5 \leq \mathrm{BMI}<24.0 \mathrm{~kg} / \mathrm{m}^{2}\right)$ or overweight $\left(B M I \geq 24.0 \mathrm{~kg} / \mathrm{m}^{2}\right)$ groups based on the criteria for Chinese adults [30].

\section{Statistical analysis}

Data were presented as mean \pm standard deviation if it was in normal distribution and medium and quartile range if it was in abnormal distribution. We used nonpaired student $t$-test if data were in normal distribution, and Chi-square analysis if data were in abnormal distribution, to analyze the differences between the two groups. We completed all statistical analyses by SAS version 9.4 (SAS Institute, Inc, Cary, NC). Formal hypothesis testing will be two-sided with a significant level of 0.05 . Because the conversion was confirmed at least twice, we determined the person-time of follow-up for each participant from January 1, 2014 to either the first onset date of the conversion, or the end of follow-up (December 31, 2018), whichever came first.

First, we used the proportional Cox regression model to evaluate the association between baseline body weight (normal weight $\boldsymbol{v} \boldsymbol{s}$. overweight) and future risk of CAP. Then, we analyzed the association between the transition and future risk of CAP. We adjusted the potential confounders in different models: model 1, adjusting for age (y) and sex; model 2, adjusting for variables in model 1 and further adjusting for baseline eGFR $(\mathrm{ml} / \mathrm{min} / 1.73$ $\mathrm{m}^{2}$ ) and hs-CRP (mg/L); and model 3, adjusting for variables in model 2 and further for baseline systolic blood pressure $(\mathrm{mmHg})$, diastolic blood pressure $(\mathrm{mmHg})$, FBG (mmol/L), HbA1c (\%), TC ( $\mathrm{mmol} / \mathrm{L}), \mathrm{TG}(\mathrm{mmol} / \mathrm{L})$, LDL-C (mmol/L), HDL-C (mmol/L).

Likelihood ratio tests were conducted to examine statistical interactions between the transition and sex, and age, in relation to the CAP by comparing- 2 log likelihood $X^{2}$ between nested models with and without the crossproduct terms.

To test the robustness of the main results, we conducted two sensitivity analyses in model 2. First, we censored participants whose baseline level of hs-CRP was $10.0 \mathrm{mg} / \mathrm{L}$ or more [31]. Then, we censored participants 
who was confirmed with metabolic abnormalities once to lower the possibility of misclassification [32].

\section{Results}

The current study included 9836 Chinese adults (4085 males and 5751 females) with metabolically healthy status at baseline, with a mean age of $35.8 \pm 9.0$ years old. Metabolically healthy status normal weight and overweight accounted for $76.4 \%(\mathrm{n}=7512)$ and $23.6 \%$ $(\mathrm{n}=2324)$, respectively. Baseline characteristics were significantly different between the two groups except for total cholesterol (Table 1).

We did not find metabolically healthy overweight $\left(B M I \geq 24.0 \mathrm{~kg} / \mathrm{m}^{2}\right)$ was associated with future risk of CAP (HR $=0.92,95 \%$ CI: 0.64, 1.32) (Additional file 1: Table S2). During 5-year follow up, the proportion who shifted from metabolically healthy to unhealthy status was $54.4 \%$ in participants with normal weight and $74.0 \%$ in participants with overweight at baseline. The cumulative proportion of developing HBP, IGR, high TC, high TG, high LDL-C, and low HDL-C was 36.4\%, 20.1\%, $11.2 \%, 15.3 \%, 18.4 \%$, and $20.0 \%$, respectively (Fig. 1). Baseline metabolically healthy overweight was associated

Table 1 The comparison of baseline characteristics according to baseline body weight in 9836 Chinese adults with metabolically healthy status

\begin{tabular}{|c|c|c|c|}
\hline Variables & $\begin{array}{l}\text { Normal weight } \\
(18.5 \leq \mathrm{BMI} \leq 23.9 \mathrm{~kg} / \\
\left.\mathrm{m}^{2}\right)\end{array}$ & $\begin{array}{l}\text { Overweight } \\
(\mathrm{BMI} \geq 24.0 \mathrm{~kg} / \\
\left.\mathrm{m}^{2}\right)\end{array}$ & $P$ value \\
\hline Sample number & 7512 & 2324 & - \\
\hline Age, y & $35.6 \pm 8.9$ & $36.3 \pm 9.3$ & $<0.001$ \\
\hline Sex, M/F, \% & $34.9 / 65.1$ & $63.1 / 36.9$ & $<0.001$ \\
\hline $\mathrm{BMI}, \mathrm{kg} / \mathrm{m}^{2}$ & $21.3 \pm 1.5$ & $25.8 \pm 1.7$ & $<0.001$ \\
\hline $\mathrm{FBG}, \mathrm{mmol} / \mathrm{L}$ & $4.8 \pm 0.4$ & $4.8 \pm 0.4$ & $<0.001$ \\
\hline $\mathrm{HbA1c}, \%$ & $5.1 \pm 0.3$ & $5.2 \pm 0.3$ & $<0.001$ \\
\hline $\mathrm{SBP}, \mathrm{mmHg}$ & $108.2 \pm 9.7$ & $112.8 \pm 8.7$ & $<0.001$ \\
\hline $\mathrm{DBP}, \mathrm{mmHg}$ & $67.1 \pm 6.9$ & $69.6 \pm 6.3$ & $<0.001$ \\
\hline $\mathrm{TC}, \mathrm{mmol} / \mathrm{L}$ & $4.4 \pm 0.6$ & $4.4 \pm 0.6$ & 0.08 \\
\hline $\mathrm{TG}, \mathrm{mmol} / \mathrm{L}$ & $0.8 \pm 0.3$ & $1.0 \pm 0.3$ & $<0.001$ \\
\hline $\mathrm{HDL}-\mathrm{C}, \mathrm{mmol} / \mathrm{L}$ & $1.5 \pm 0.3$ & $1.3 \pm 0.3$ & $<0.001$ \\
\hline LDL-C, mmol/L & $2.4 \pm 0.5$ & $2.6 \pm 0.5$ & $<0.001$ \\
\hline $\mathrm{Hs}-\mathrm{CRP}, \mathrm{mg} / \mathrm{L}^{*}$ & $0.36(0.2,0.7)$ & $0.7(0.38,1.34)$ & $<0.001$ \\
\hline $\begin{array}{l}\text { eGFR, ml/ } \\
\mathrm{min} / 1.73 \mathrm{~m}^{2}\end{array}$ & $112.7 \pm 12.3$ & $109.8 \pm 12.6$ & $<0.001$ \\
\hline
\end{tabular}

$M$, male; $F$, female; BMI, body mass index; FBG, fasting blood glucose; $\mathrm{HbA} 1 \mathrm{C}$, glycated hemoglobin A1c; SBP, systolic blood pressure; DBP, diastolic blood pressure; TC, total cholesterol; TG, total glycerides; HDL-C, high-densitylipoprotein cholesterol; LDL-C, low-density-lipoprotein cholesterol; hsCRP, high sensitivity C-reactive protein; eGFR, estimated glomerular filtration rate

Metabolically healthy status was defined no history of hypertension, diabetes mellitus, cardiovascular disease, dyslipidemia, and cancer, and normal blood pressure, $\mathrm{FBG}, \mathrm{HbA} 1 \mathrm{c}$, and lipid profiles at baseline

*Abnormal distribution, data was represented by medium plus quartile range with high risk of developing high blood pressure [hazards ratio $(\mathrm{HR})=1.23$; 95\% confidence interval $(\mathrm{CI}): 1.14,1.33$ ] and impaired glucose regulation ( $\mathrm{HR}=1.15 ; 95 \% \mathrm{CI}: 1.04$, 1.28 ) in fully adjusted model, compared to metabolically healthy normal weight group (Table 2). Baseline healthy overweight was associated with high TC, high TG, high LDL-C, and low HDL-C in age- and sex- adjusted model, however, the association lost significance after further adjusting baseline blood pressure, FBG, HbA1c, and lipid profile except a marginal association between metabolically healthy overweight and high TG $(\mathrm{HR}=1.12,95 \% \mathrm{CI}$ : 1.001, 1.25, $p=0.046$ ) (Table 2).

We have identified 133 incident cases of CAP during follow up. Compared to those who remained metabolically healthy status, we found that transition to high blood pressure, high TC, and high LDL-C during follow up were associated a high likelihood of developing CAP, regardless of baseline body weight status (Table 3). When considering the transition to impaired glucose regulation, high TG, and low HDL-C, the association only remained in participants with baseline metabolically healthy overweight (Table 3).

We found that the association between the transition to metabolic abnormalities and future risk of CAP was modified by age (all $p<0.01$ ), but not sex (Additional file 1: Table S3). The association between the transition to metabolic abnormalities and future risk of CAP was more pronounced in participants aged 34 years or more (Additional file 1: Table S3). Excluding participants whose baseline level of hs-CRP was $10 \mathrm{mg} / \mathrm{L}$ did not substantially change the association (Additional file 1 : Table S4). Excluding participants who were confirmed with metabolic abnormalities once during follow up, the association remained a similar trend. However, the association lost significance in some groups because of small incident cases of CAP (Additional file 1: Table S5).

The risk of CAP increased simultaneously with the increase of metabolic abnormalities, compared with those remained metabolically healthy status ( $p$ trend $<0.001$, Additional file 1: Table S6).

\section{Discussion}

In the current study including 9836 Chinese adults with metabolically healthy status, we found that the transition to metabolic abnormalities were associated with high risk of developing CAP, after adjusting a series of traditional risk factors, including blood pressure, FBG, HbA1c, lipid profiles, eGFR, and hs-CRP. If the participants were overweight at baseline but remained metabolically healthy status, the risk of CAP was similar with those whose baseline body weight were normal and remained metabolically healthy during the follow up. 


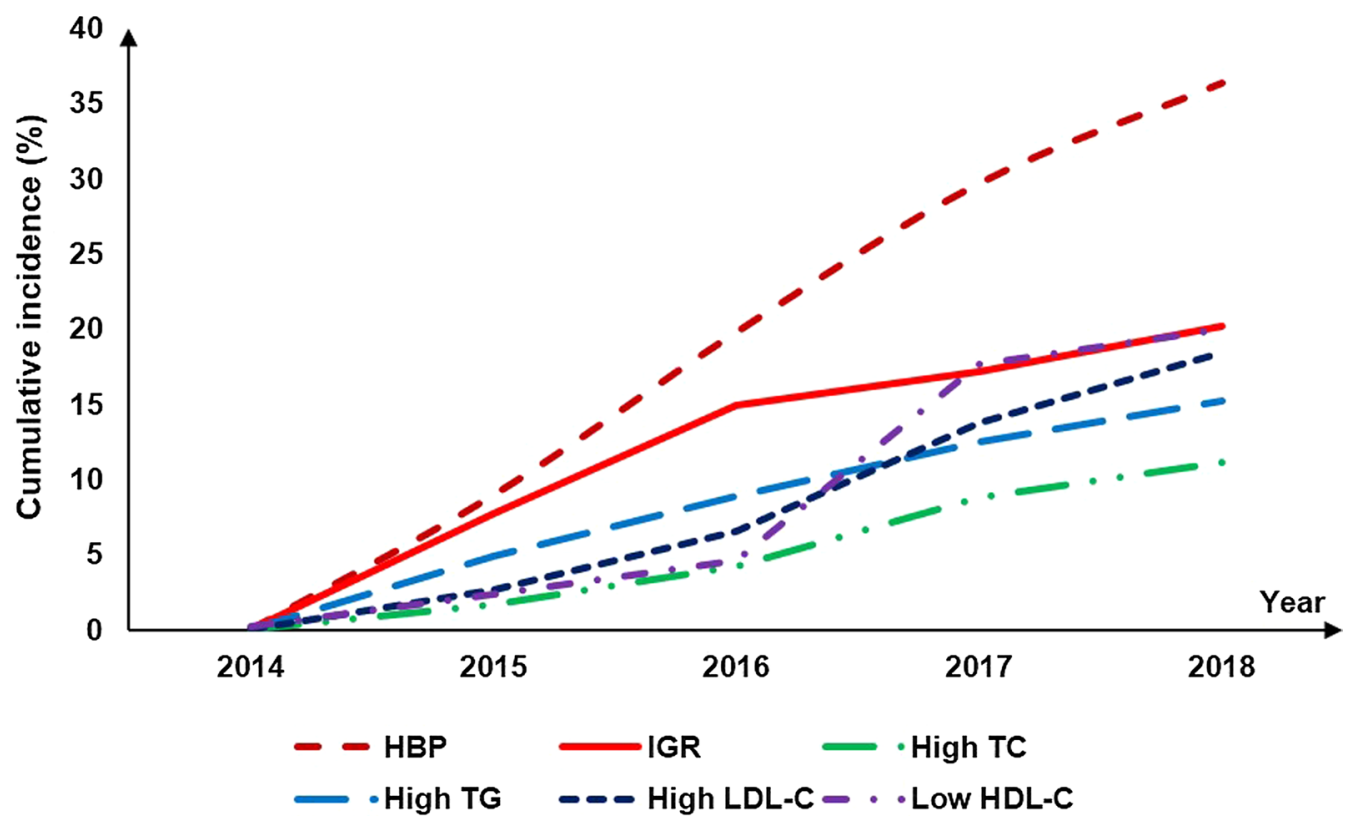

Fig. 1 The cumulative proportion of different types of metabolic abnormalities during 5-year follow up. HBP, high blood pressure; IGR, impaired glucose regulation; TC, total cholesterol; TG, total triglycerides; LDL-C, low-density lipoprotein cholesterol; HDL-C, high-density lipoprotein cholesterol. Criteria: HBP: systolic blood pressure $\geq 130 \mathrm{mmHg}$ and/or diastolic blood pressure $\geq 80 \mathrm{mmHg}$; IGR: fasting blood glucose $\geq 5.6 \mathrm{mmol} / \mathrm{L}$ and/or HbA1C $\geq 5.6 \%$; high TC: $\geq 5.72 \mathrm{mmol} / \mathrm{L}$; high TG: $\geq 1.7 \mathrm{mmol} / \mathrm{L}$; high LDL-C: $\geq 3.4 \mathrm{mmol} / \mathrm{L}$; low HDL-C: $<0.9 \mathrm{mmol} / \mathrm{L}$ in men and $<1.0 \mathrm{mmol} / \mathrm{L}$ in women

Our results did not support the hypothesis that baseline metabolically healthy obesity was associated with high risk of CAP. Limited to studies in general population with large sample size $(\mathrm{n} \geq 1000)$, three cross-sectional studies have been performed in Korean adults in which atherosclerosis was assessed by coronary artery calcium score $[10,12,13]$. One reported metabolically healthy status was more closely associated with atherosclerosis than obesity [10] while another two found that participants with metabolically healthy obesity had a higher prevalence of atherosclerosis than their metabolically healthy normal weight counterparts $[12,13]$. Our results were consistent with one cross-sectional study in which atherosclerosis was assessed by the same method (ultrasound B model) [6]. They found that participants with normal weight and metabolic abnormalities, but not those with overweight but with metabolically healthy, was associated with high prevalence of atherosclerosis [6]. As for cohort study, Kim et al. [11] reported baseline metabolically healthy overweight ( $\mathrm{HR}=1.24 ; 95 \% \mathrm{CI}: 1.12,1.38)$ and obesity ( $\mathrm{HR}=1.54$; $95 \% \mathrm{CI}: 1.38,1.72)$ were associated with CAP in 6543 men with a median follow up of 4.2 years. However, as the author acknowledged that including only men were in the study was obvious a limitation. The different definition of metabolically healthy obesity, in combination with ethnicity, population, and statistical method, was blamed for the discrepancies among the studies [15].

One possible explanation was that metabolically healthy obesity was defined based on BMI and BMI was often blamed for its shortcomings of not distinguishing body fat from lean body mass. Metabolically healthy obese might have a better adipose tissue function and less ectopic fat storage than persons with both obesity and metabolic abnormalities. A mendelian randomization study using summarized data including 24 metabolic phenotypes from 10 consortiums reported that the odds ratios and 95\% CIs of a 1-SD increase in body fat mass ranged from 1.11 to 1.41 (all $p<0.05$ ) for type 2 diabetes mellitus, hypertension, coronary artery disease, myocardial infarction, and ischemic stroke [33]. Another mendelian study performed in 367,703 UK Biobank participants reported that fat mass index associated stronger with aortic valve stenosis than BMI (1.06 for per $1 \mathrm{~kg} / \mathrm{m}^{2}$ vs. 1.46 for fat mass index) [34]. Another reason for heterogeneity was lack of consensus of definition of metabolically healthy obesity [5].

Another critical point was the transition from baseline metabolically healthy to metabolic abnormalities, which was previously neglected among previous studies. Chang et al. [13] also pointed out the association between baseline metabolically healthy obesity and atherosclerosis 
Table 2 Risk of developing different metabolic abnormalities during follow-up, according to baseline body weight status in 9836 Chinese adults who were metabolically healthy

\begin{tabular}{|c|c|c|}
\hline Outcome & $\begin{array}{l}\text { Metabolically healthy } \\
\text { normal weight } \\
\left(\mathrm{BMI}<24.0 \mathrm{~kg} / \mathrm{m}^{2}\right)\end{array}$ & $\begin{array}{l}\text { Metabolically } \\
\text { healthy overweight } \\
\left(\mathrm{BMI} \geq 24.0 \mathrm{~kg} / \mathrm{m}^{2}\right)\end{array}$ \\
\hline \multicolumn{3}{|l|}{$H B P$} \\
\hline Number of participants & 7512 & 2324 \\
\hline Incident case & 2400 & 1177 \\
\hline Model 1 & $\operatorname{Ref}(1.0)$ & $1.50(1.4,1.61)$ \\
\hline Model 2 & $\operatorname{Ref}(1.0)$ & $1.49(1.39,1.6)$ \\
\hline Model 3 & $\operatorname{Ref}(1.0)$ & $1.23(1.14,1.33)$ \\
\hline \multicolumn{3}{|l|}{$I G R$} \\
\hline Number of participants & 7512 & 2324 \\
\hline Incident case & 1394 & 594 \\
\hline Model 1 & $\operatorname{Ref}(1.0)$ & $1.36(1.24,1.51)$ \\
\hline Model 2 & $\operatorname{Ref}(1.0)$ & $1.31(1.2,1.49)$ \\
\hline Model 3 & $\operatorname{Ref}(1.0)$ & $1.15(1.04,1.28)$ \\
\hline \multicolumn{3}{|l|}{ High TC } \\
\hline Number of Participants & 7512 & 2,324 \\
\hline Incident case & 836 & 266 \\
\hline Model 1 & $\operatorname{Ref}(1.0)$ & $1.08(0.94,1.25)$ \\
\hline Model 2 & $\operatorname{Ref}(1.0)$ & $1.07(0.93,1.24)$ \\
\hline Model 3 & $\operatorname{Ref}(1.0)$ & $1.03(0.89,1.19)$ \\
\hline \multicolumn{3}{|l|}{ High TG } \\
\hline Number of participants & 7512 & 2324 \\
\hline Incident case & 908 & 595 \\
\hline Model 1 & $\operatorname{Ref}(1.0)$ & $1.79(1.6,1.99)$ \\
\hline Model 2 & $\operatorname{Ref}(1.0)$ & $1.77(1.59,1.97)$ \\
\hline Model 3 & $\operatorname{Ref}(1.0)$ & $1.12(1.001,1.25)$ \\
\hline \multicolumn{3}{|l|}{ High LDL-C } \\
\hline Number of participants & 7512 & 2324 \\
\hline Incident case & 1264 & 550 \\
\hline Model 1 & $\operatorname{Ref}(1.0)$ & $1.31(1.18,1.45)$ \\
\hline Model 2 & $\operatorname{Ref}(1.0)$ & $1.3(1.17,1.44)$ \\
\hline Model 3 & $\operatorname{Ref}(1.0)$ & $0.99(0.89,1.11)$ \\
\hline \multicolumn{3}{|l|}{ Low HDL-C } \\
\hline Number of participants & 7512 & 2324 \\
\hline Incident case & 371 & 238 \\
\hline Model 1 & $\operatorname{Ref}(1.0)$ & $1.78(1.5,2.1)$ \\
\hline Model 2 & $\operatorname{Ref}(1.0)$ & $1.75(1.48,2.08)$ \\
\hline Model 3 & $\operatorname{Ref}(1.0)$ & $0.99(0.83,1.18)$ \\
\hline
\end{tabular}

If the number " 1 " is not included in the confidence interval, it means significant Model 1: adjusting for age and sex. Model 2: adjusting for variables in model 1 and estimated glomerular filtration rate $\left(\mathrm{ml} / \mathrm{min} / 1.73 \mathrm{~m}^{2}\right)$, and high sensitivity C-reactive protein (mg/L). Model 3: adjusting for variables in model 2 and systolic blood pressure $(\mathrm{mmHg})$, diastolic blood pressure $(\mathrm{mmHg})$, FBG $(\mathrm{mmol} / \mathrm{L})$, HbA1c $(\%)$, TC $(\mathrm{mmol} / \mathrm{L})$, TG $(\mathrm{mmol} / \mathrm{L})$, LDL-C $(\mathrm{mmol} / \mathrm{L})$, HDL-C ( $\mathrm{mmol} / \mathrm{L})$

HBP, high blood pressure; FBG, fasting blood glucose; HbA1c, glycated hemoglobin A1 C; IGR, impaired glucose regulation; TC, total cholesterol; TG, total triglycerides; LDL-C, low-density lipoprotein cholesterol; HDL-C, high-density lipoprotein cholesterol

Definition: Metabolically healthy was defined as participants without history of high blood pressure, diabetes mellitus, cardiovascular disease, dyslipidemia, and
Table 2 (continued)

cancer but with normal blood pressure, FBG, HbA1c, TC, TG, LDL-C, and HDL-C. Criteria for metabolic abnormality: $\mathrm{HBP}$ (systolic blood pressure $\geq 130 \mathrm{mmHg}$ or diastolic blood pressure $\geq 80 \mathrm{mmHg}$ ); IGR (FBG $\geq 5.6 \mathrm{mmol} / \mathrm{L}$ or $\mathrm{HbA} 1 \mathrm{c} \geq 5.7 \%$ ); high TC, $\geq 5.72 \mathrm{mmol} / \mathrm{L}$; high TG, $\geq 1.7 \mathrm{mmol} / \mathrm{L}$; high LDL-C, $\geq 3.4 \mathrm{mmol} / \mathrm{L}$; low $\mathrm{HDL}-\mathrm{C},<0.9 \mathrm{mmol} / \mathrm{L}$ in $\mathrm{men}$ and $<1.0 \mathrm{mmol} / \mathrm{L}$ in women

could be mediated by components of metabolic abnormalities. Further, the Nurse's Health Study reported that $84 \%$ of women with obesity and $68 \%$ of women with normal-weight were confirmed with metabolic abnormalities after 20 years [24], which indicated that metabolically healthy was unstable and eventually transited to unhealthy status. Lin et al. have performed a very interesting cohort study in 6220 Chinese adults with metabolically healthy $(\leq 2$ components of metabolic syndrome based on ATP III). Transition to metabolic abnormalities was associated with an odd ratio of 2.52 (95\%CI: 1.89 , 3.36) for the risk of atherosclerosis compared with their normal weight counterparts [23]. Similar with Lin's study, we also confirmed that the transition was associated with future risk of atherosclerosis. In addition, we found that different types of metabolic abnormalities differed in their effects on the development of atherosclerosis. Abnormalities of blood pressure, TC, and LDL-C were associated a high likelihood of developing atherosclerosis in both metabolically healthy overweight and normal weight groups while the occurrence of abnormalities of glucose regulation, TG, and HDL-C were associated with atherosclerosis only in those who were overweight at baseline.

It is not surprising that we found that age modified the association between the transition and atherosclerosis. In other words, the association remained in elder ( $\geq 34$ years), but not younger participants. Previous studies have proved that the prevalence of both total atherosclerotic related cardiovascular diseases [35] and peripheral artery diseases increased with age [36]. We did not find an interaction of sex with the association, which was consistent with previous studies [13, 15].

The strengthens of the current study includes more stricter definition of metabolically healthy status, a prospective study design, and a fully adjustment of traditional risk factors including blood pressure, FBG, HbA1c, and lipid profile though they were in normal range. However, some limitations must be addressed. First, the history of metabolic diseases was self-reported, which was lower than national prevalence. We thus excluded those with abnormalities at baseline, which could reduce the possibility of misclassification. Second, information about medical intervention, diet, and physical activities was deficient. Medical treatment such as aspirin was deficient, which was known to be associated with the 
Table 3 Risk of incident carotid artery plaque by baseline body weight status and transition to metabolic abnormalities in 9836 Chinese adults

\begin{tabular}{|c|c|c|c|c|}
\hline \multirow[t]{3}{*}{ Models } & \multirow{2}{*}{\multicolumn{2}{|c|}{$\begin{array}{l}\text { Metabolically healthy normal weight } \\
\left(\mathrm{n}=7512, \mathrm{BMI}<24.0 \mathrm{~kg} / \mathrm{m}^{2}\right)\end{array}$}} & \multirow{2}{*}{\multicolumn{2}{|c|}{$\begin{array}{l}\text { Metabolically healthy overweight } \\
\left(\mathrm{n}=2324, \mathrm{BMI} \geq 24.0 \mathrm{~kg} / \mathrm{m}^{2}\right)\end{array}$}} \\
\hline & & & & \\
\hline & Stable & Transition to HBP & Stable & Transition to HBP \\
\hline Number of participants & 5112 & 2400 & 1147 & 1177 \\
\hline CAP case & 35 & 50 & 14 & 34 \\
\hline Model 1 & $\operatorname{Ref}(1.0)$ & $1.64(1.05,2.55)$ & $1.24(0.66,2.31)$ & $2.35(1.45,3.83)$ \\
\hline Model 2 & $\operatorname{Ref}(1.0)$ & $1.62(1.04,2.53)$ & $1.22(0.62,2.29)$ & $2.36(1.45,3.85)$ \\
\hline \multirow[t]{2}{*}{ Model 3} & $\operatorname{Ref}(1.0)$ & $1.69(1.06,2.68)$ & $1.18(0.62,2.23)$ & $2.29(1.35,3.87)$ \\
\hline & Stable & Transition to IGR & Stable & Transition to IGR \\
\hline Number of participants & 6118 & 1394 & 1730 & 594 \\
\hline CAP case & 56 & 29 & 24 & 24 \\
\hline Model 1 & $\operatorname{Ref}(1.0)$ & $1.22(0.78,1.93)$ & $1.18(0.73,1.91)$ & $2.17(1.34,3.53)$ \\
\hline Model 2 & $\operatorname{Ref}(1.0)$ & $1.2(0.76,1.91)$ & $1.19(0.73,1.93)$ & $2.15(1.33,3.51)$ \\
\hline \multirow[t]{2}{*}{ Model 3} & Ref (1.0) & $1.17(0.73,1.87)$ & $1.11(0.67,1.81)$ & $1.95(1.15,3.3)$ \\
\hline & Stable & Transition to high TC & Stable & Transition to high TC \\
\hline Number of participants & 6676 & 836 & 2058 & 266 \\
\hline CAP case & 61 & 24 & 36 & 12 \\
\hline Model 1 & $\operatorname{Ref}(1.0)$ & $2.26(1.39,3.65)$ & $1.45(0.95,2.19)$ & $2.7(1.45,5.03)$ \\
\hline Model 2 & $\operatorname{Ref}(1.0)$ & $2.25(1.38,3.66)$ & $1.45(0.96,2.2)$ & $2.71(1.46,5.05)$ \\
\hline \multirow[t]{2}{*}{ Model 3} & $\operatorname{Ref}(1.0)$ & $2.04(1.22,3.43)$ & $1.33(0.87,2.05)$ & $2.34(1.21,4.53)$ \\
\hline & Stable & Transition to high TG & Stable & Transition to high TG \\
\hline Number of participants & 6604 & 908 & 1729 & 595 \\
\hline CAP case & 69 & 16 & 27 & 21 \\
\hline Model 1 & $\operatorname{Ref}(1.0)$ & $1.23(0.71,2.12)$ & $1.14(0.73,1.79)$ & $2.37(1.44,3.9)$ \\
\hline Model 2 & $\operatorname{Ref}(1.0)$ & $1.23(0.72,2.13)$ & $1.15(0.74,1.81)$ & $2.37(1.44,3.92)$ \\
\hline \multirow[t]{2}{*}{ Model 3} & $\operatorname{Ref}(1.0)$ & $1.23(0.69,2.2)$ & $1.08(0.68,1.71)$ & $2.27(1.30,3.95)$ \\
\hline & Stable & Transition to high LDL-C & Stable & Transition to high LDL-C \\
\hline Number of participants & 6248 & 1264 & 1774 & 550 \\
\hline CAP case & 51 & 34 & 31 & 17 \\
\hline Model 1 & $\operatorname{Ref}(1.0)$ & $2.26(1.46,3.5)$ & $1.59(1.01,2.49)$ & $2.39(1.38,4.16)$ \\
\hline Model 2 & $\operatorname{Ref}(1.0)$ & $2.27(1.47,3.51)$ & $1.6(1.02,2.51)$ & $2.4(1.38,4.17)$ \\
\hline \multirow[t]{2}{*}{ Model 3} & $\operatorname{Ref}(1.0)$ & $1.95(1.20,3.17)$ & $1.52(0.95,2.42)$ & $2.03(1.11,3.73)$ \\
\hline & Stable & Transition to low HDL-C & Stable & Transition to low HDL-C \\
\hline Number of participants & 7403 & 109 & 2252 & 72 \\
\hline CAP case & 83 & 2 & 45 & 3 \\
\hline Model 1 & $\operatorname{Ref}(1.0)$ & $1.68(0.41,6.83)$ & $1.37(0.95,1.98)$ & $4.55(1.43,14.53)$ \\
\hline Model 2 & $\operatorname{Ref}(1.0)$ & $1.65(0.41,6.71)$ & $1.37(0.95,1.99)$ & $4.51(1.41,14.4)$ \\
\hline Model 3 & $\operatorname{Ref}(1.0)$ & $1.61(0.39,6.69)$ & $1.27(0.86,1.87)$ & $4.62(1.4,15.22)$ \\
\hline
\end{tabular}

If the number " 1 " is not included in the confidence interval, it means significant

Model 1: adjusting for age and sex. Model 2: adjusting for variables in model 1 and estimated glomerular filtration rate ( $\left.\mathrm{ml} / \mathrm{min} / 1.73 \mathrm{~m}^{2}\right)$, and high sensitivity C-reactive protein (mg/L). Model 3: adjusting for variables in model 2 and systolic blood pressure (mmHg), diastolic blood pressure $(\mathrm{mmHg}), \mathrm{FBG}(\mathrm{mmol} / \mathrm{L}), \mathrm{HbA} 1 \mathrm{c}(\%)$, TC $(\mathrm{mmol} / \mathrm{L})$, TG ( $\mathrm{mmol} / \mathrm{L}), \mathrm{LDL}-\mathrm{C}(\mathrm{mmol} / \mathrm{L}), \mathrm{HDL}-\mathrm{C}(\mathrm{mmol} / \mathrm{L})$

HBP, high blood pressure; FBG, fasting blood glucose; HbA1c, glycated hemoglobin A1c; IGR, impaired glucose regulation; TC, total cholesterol; TG, total triglycerides; LDL-C, low-density lipoprotein cholesterol; HDL-C, high-density lipoprotein cholesterol

Definition: Metabolically healthy was defined as participants without history of high blood pressure, diabetes mellitus, cardiovascular disease, dyslipidemia, and cancer but with normal blood pressure, $\mathrm{FBG}, \mathrm{HbA1C}, \mathrm{TC}, \mathrm{TG}, \mathrm{LDL}-\mathrm{C}$, and $\mathrm{HDL}-\mathrm{C}$. Criteria for metabolic abnormality: $\mathrm{HBP}$ (systolic blood pressure $\geq 130 \mathrm{mmHg}$ or diastolic blood pressure $\geq 80 \mathrm{mmHg}$ ); IGR (FBG $\geq 5.6 \mathrm{mmol} / \mathrm{L}$ or HbA1c $\geq 5.7 \%$ ); high TC, $\geq 5.72 \mathrm{mmol} / \mathrm{L}$; high TG, $\geq 1.7 \mathrm{mmol} / \mathrm{L}$; high LDL-C, $\geq 3.4 \mathrm{mmol} / \mathrm{L}$; low HDL-C, $<0.9 \mathrm{mmol} / \mathrm{L}$ in $\mathrm{men}$ and $<1.0 \mathrm{mmol} / \mathrm{L}$ in women 
development of atherosclerosis [37]. The information on lipid-lowering drugs such as statins was also deficient, which could lead to misclassification of dyslipidemia and was associated with cardiovascular diseases [38]. We cannot exclude the possibility that some participants were on diet and this might distract the results. Similarly, we did not collect information on waist circumference. Waist circumference is better to predict visceral adipose tissue than BMI and it is closer associated with CAP [39], however, $\mathrm{BMI}$ is the most widely used parameter to diagnose overweight and obesity. Third, all the participants were recruited from those who underwent health checkup in our hospital. It accounted for a small proportion of the total residents; thus, the generalizability of study population was limited. Fourth, the ideal time for fasting when drawing blood might be $8-10 \mathrm{~h}$. However, it was shorter (at least $6 \mathrm{~h}$ fasting) in the current study and this might have some effects on the value of fasting blood glucose and lipid profiles. Finally, the number of incident CAP cases was small in the current study. Multiple-center based cohort studies with a face-to-face interview about history of diseases and medical information were needed to duplicate our results.

\section{Conclusions}

The transition from baseline metabolically healthy to metabolic abnormalities was associated with high risk of incident atherosclerosis. Six out of ten participants developed at least one type of metabolically abnormalities during follow up, and the proportion was higher in participants with overweight, compared with those with normal weight at baseline. Early interventions focusing on both baseline body weight and the occurrence of metabolic abnormalities are meaningful to reduce atherosclerosis related disability and mortality.

\section{Supplementary Information}

The online version contains supplementary material available at https://doi. org/10.1186/s12872-021-02279-w.

Additional file 1. The supplemental figure and tables.

\section{Acknowledgements}

None.

\section{Authors' contributions}

Tan T and Zhou Y.Q. researched data, performed the analyses, and drafted the manuscript; Wan Y.P. and Fan Z.P. researched data; Gao X. and Xu R.Y. reviewed/ edited the manuscript. All authors read and approved the final manuscript.

\section{Funding}

The study was supported by the grant from Shanghai Key Laboratory of Pediatric Gastroenterology and Nutrition (No.17DZ2272000).

\section{Available of data and materials}

The SAS code and data that support the findings of this study on GitHub website: https://github.com/xurenying7465/xurenying7465.

\section{Declarations}

Ethics approval and consent to participate

The study protocol was approved by the Ethical Committee of Ren Ji Hospital, School of Medicine, Shanghai Jiao Tong University. As a de-identified secondary data analysis, patients' consent was waived by the Ethical Committee of Ren Ji Hospital, School of Medicine, Shanghai Jiao Tong University. All methods were carried out in accordance with relevant guidelines and regulations in the declaration section under the ethics approval and consent to participate.

\section{Consent for publication}

Written informed consent for publication was obtained.

\section{Competing interests}

The authors declared no conflict of interests.

\section{Author details}

${ }^{1}$ Department of Clinical Nutrition, Ren Ji Hospital South Campus, School of Medicine, Shanghai Jiao Tong University, Shanghai 200127, China. ${ }^{2}$ Shanghai Key Laboratory of Pediatrics Gastroenterology and Nutrition, Shanghai, China. ${ }^{3}$ Department of Digestion, Ren Ji Hospital South Campus, School of Medicine, Shanghai Jiao Tong University, Shanghai, China. ${ }^{4}$ Department of Nutrition Science, The Pennsylvania State University, State College, PA, USA.

Received: 13 June 2021 Accepted: 20 September 2021

Published online: 28 September 2021

\section{References}

1. Kauw F, Takx RAP, de Jong H, Velthuis BK, Kappelle LJ, Dankbaar JW. Clinical and imaging predictors of recurrent ischemic stroke: a systematic review and meta-analysis. Cerebrovasc Dis. 2018;45(5-6):279-87.

2. Palasubramaniam J, Wang X, Peter K. Myocardial infarction-from atherosclerosis to thrombosis. Arterioscler Thromb Vasc Biol. 2019;39(8):e176-85.

3. Arntzen KA, Schirmer H, Johnsen SH, Wilsgaard T, Mathiesen EB. Carotid atherosclerosis predicts lower cognitive test results: a 7-year follow-up study of 4371 stroke-free subjects - the Tromso study. Cerebrovasc Dis. 2012;33(2):159-65.

4. Vidal-Perez R, Franco-Gutierrez R, Perez-Perez AJ, Franco-Gutierrez V, Gascon-Vazquez A, Lopez-Lopez A, et al. Subclinical carotid atherosclerosis predicts all-cause mortality and cardiovascular events in obese patients with negative exercise echocardiography. World J Cardiol. 2019;11(1):24-37.

5. Jung $\mathrm{CH}$, Lee WJ, Song KH. Metabolically healthy obesity: a friend or foe? Korean J Intern Med. 2017;32(4):611-21.

6. Yoo HJ, Hwang SY, Hong HC, Choi HY, Seo JA, Kim SG, et al. Association of metabolically abnormal but normal weight (MANW) and metabolically healthy but obese $(\mathrm{MHO})$ individuals with arterial stiffness and carotid atherosclerosis. Atherosclerosis. 2014;234(1):218-23.

7. Sung KC, Cha SC, Sung JW, So MS, Byrne CD. Metabolically healthy obese subjects are at risk of fatty liver but not of pre-clinical atherosclerosis. Nutr Metab Cardiovasc Dis. 2014;24(3):256-62.

8. Kim HN, Kim SH, Eun YM, Song SW. Obesity with metabolic abnormality is associated with the presence of carotid atherosclerosis in Korean men: a cross-sectional study. Diabetol Metab Syndr. 2015;7:68.

9. Yoon ES, Heffernan KS, Jae SY, Kim HJ, Bunsawat K, Fernhall B. Metabolically healthy obesity and subclinical atherosclerosis in persons with spinal cord injury. J Rehabil Med. 2018;50(7):613-8.

10. Rhee EJ, Seo MH, Kim JD, Jeon WS, Park SE, Park CY, et al. Metabolic health is more closely associated with coronary artery calcification than obesity. PLOS ONE. 2013;8(9):e74564.

11. Kim TJ, Shin HY, Chang Y, Kang M, Jee J, Choi YH, et al. Metabolically healthy obesity and the risk for subclinical atherosclerosis. Atherosclerosis. 2017;262:191-7. 
12. Jung CH, Lee MJ, Hwang JY, Jang JE, Leem J, Yang DH, et al. Association of metabolically healthy obesity with subclinical coronary atherosclerosis in a Korean population. Obesity (Silver Spring). 2014;22(12):2613-20.

13. Chang Y, Kim BK, Yun KE, Cho J, Zhang Y, Rampal S, et al. Metabolicallyhealthy obesity and coronary artery calcification. J Am Coll Cardiol. 2014;63(24):2679-86.

14. Jae SY, Franklin B, Choi YH, Fernhall B. Metabolically healthy obesity and carotid intima-media thickness: effects of cardiorespiratory fitness. Mayo Clin Proc. 2015;90(9):1217-24.

15. Kowall B, Lehmann N, Mahabadi AA, Moebus S, Erbel R, Jockel KH, et al. Associations of metabolically healthy obesity with prevalence and progression of coronary artery calcification: results from the Heinz Nixdorf Recall Cohort Study. Nutr Metab Cardiovasc Dis. 2019;29(3):228-35.

16. Talavera-Garcia E, Delgado-Lista J, Garcia-Rios A, Delgado-Casado N Gomez-Luna P, Gomez-Garduno A, et al. Influence of obesity and metabolic disease on carotid atherosclerosis in patients with coronary artery disease CordioPrev Study. PLOS ONE. 2016;11(4):e0153096.

17. Itoh H, Kaneko H, Kiriyama H, Yoshida Y, Nakanishi K, Mizuno Y, et al. Effect of metabolically healthy obesity on the development of carotid plaque in the general population: a community-based cohort study. J Atheroscler Thromb. 2020;27(2):155-63.

18. Khan UI, Wang D, Thurston RC, Sowers M, Sutton-Tyrrell K, Matthews $\mathrm{KA}$, et al. Burden of subclinical cardiovascular disease in "metabolically benign" and "at-risk" overweight and obese women: the Study of Women's Health Across the Nation (SWAN). Atherosclerosis. 2011;217(1):179-86.

19. Shargorodsky M. Vascular impact of metabolic syndrome in subjects with normal weight, overweight, or obesity: is normal weight sufficient for vascular health? J Am Coll Nutr. 2015;34(6):515-20.

20. Lee HJ, Choi EK, Lee SH, Kim YJ, Han KD, Oh S. Risk of ischemic stroke in metabolically healthy obesity: a nationwide population-based study. PLOS ONE. 2018;13(3):e0195210.

21. Zhang N, Liang G, Liu M, Zheng G, Yu H, Shi Y, et al. Metabolically healthy obesity increases the prevalence of stroke in adults aged 40 years or older: result from the China National Stroke Screening survey. Prev Med. 2021;148:106551.

22. Ma LZ, Sun FR, Wang ZT, Tan L, Hou XH, Ou YN, et al. Metabolically healthy obesity and risk of stroke: a meta-analysis of prospective cohort studies. Ann Transl Med. 2021;9(3):197.

23. Lin L, Zhang J, Jiang L, Du R, Hu C, Lu J, et al. Transition of metabolic phenotypes and risk of subclinical atherosclerosis according to BMI: a prospective study. Diabetologia. 2020;63:1312-23.

24. Eckel N, Li Y, Kuxhaus O, Stefan N, Hu FB, Schulze MB. Transition from metabolic healthy to unhealthy phenotypes and association with cardiovascular disease risk across BMI categories in 90257 women (the Nurses' Health Study): 30 year follow-up from a prospective cohort study. Lancet Diabetes Endocrinol. 2018;6(9):714-24.

25. Polak JF, Szklo M, Kronmal RA, Burke GL, Shea S, Zavodni AE, et al. The value of carotid artery plaque and intima-media thickness for incident cardiovascular disease: the multi-ethnic study of atherosclerosis. J Am Heart Assoc. 2013;2(2):e000087.

26. Kong X, Ma Y, Chen J, Luo Q, Yu X, Li Y, et al. Evaluation of the chronic kidney disease epidemiology collaboration equation for estimating glomerular filtration rate in the Chinese population. Nephrol Dial Transplant. 2013;28(3):641-51.

27. Mathiesen EB, Johnsen $\mathrm{SH}$. Ultrasonographic measurements of subclinical carotid atherosclerosis in prediction of ischemic stroke. Acta Neurol Scand Suppl. 2009;189:68-72.

28. Whelton PK, Carey RM, Aronow WS, Casey DE Jr, Collins KJ, Dennison Himmelfarb C, et al. 2017 ACC/AHA/AAPA/ABC/ACPM/AGS/APhA/ASH/ ASPC/NMA/PCNA guideline for the prevention, detection, evaluation, and management of high blood pressure in adults: a report of the American College of Cardiology/American Heart Association task force on clinical practice guidelines. Hypertension. 2018;71(6):e13-115.

29. American DA. Diagnosis and classification of diabetes mellitus. Diabetes Care. 2014;37(Suppl 1):S81-90.

30. Zhou B, Cooperative Meta-Analysis Group of China Obesity Task F. [Predictive values of body mass index and waist circumference to risk factors of related diseases in Chinese adult population]. Zhonghua Liu Xing Bing Xue Za Zhi. 2002;23(1):5-10.

31. Wu Z, Huang Z, Jin W, Rimm EB, Lichtenstein AH, Kris-Etherton PM, et al Peripheral inflammatory biomarkers for myocardial infarction risk: a prospective community-based study. Clin Chem. 2017;63(3):663-72.

32. Xu R, Gao X, Wan Y, Fan Z. Association of metabolically healthy overweight phenotype with abnormalities of glucose levels and blood pressure among Chinese adults. JAMA Netw Open. 2019;2(10):e1914025.

33. Si S, Tewara MA, Li Y, Li W, Chen X, Yuan T, et al. Causal pathways from body components and regional fat to extensive metabolic phenotypes: a Mendelian randomization study. Obesity (Silver Spring). 2020;28(8):1536-49.

34. Larsson SC, Back M, Rees JMB, Mason AM, Burgess S. Body mass index and body composition in relation to 14 cardiovascular conditions in UK Biobank: a Mendelian randomization study. Eur Heart J. 2020;41(2):221-6.

35. Kim H, Kim S, Han S, Rane PP, Fox KM, Qian Y, et al. Prevalence and incidence of atherosclerotic cardiovascular disease and its risk factors in Korea: a nationwide population-based study. BMC Public Health. 2019;19(1):1112.

36. Song P, Rudan D, Wang M, Chang X, Rudan I. National and subnational estimation of the prevalence of peripheral artery disease (PAD) in China: a systematic review and meta-analysis. J Glob Health. 2019;9(1):010601.

37. Beckman JA. Antithrombotic therapies in cerebrovascular disease: what should we use as secondary prevention in patients with carotid artery disease? Catheter Cardiovasc Interv. 2009;74(Suppl 1):S12-6.

38. Chou R, Dana T, Blazina I, Daeges M, Jeanne TL. Statins for prevention of cardiovascular disease in adults: evidence report and systematic review for the US preventive services task force. JAMA. 2016;316(19):2008-24.

39. Imahori $Y$, Mathiesen EB, Morgan KE, Frost C, Hughes AD, Hopstock LA, et al. The association between anthropometric measures of adiposity and the progression of carotid atherosclerosis. BMC Cardiovasc Disord. 2020;20(1):138.

\section{Publisher's Note}

Springer Nature remains neutral with regard to jurisdictional claims in published maps and institutional affiliations.

Ready to submit your research? Choose BMC and benefit from

- fast, convenient online submission

- thorough peer review by experienced researchers in your field

- rapid publication on acceptance

- support for research data, including large and complex data types

- gold Open Access which fosters wider collaboration and increased citations

- maximum visibility for your research: over 100M website views per year

At BMC, research is always in progress.

Learn more biomedcentral.com/submissions 